\title{
LOS ALBORES DE LA INDUSTRIA SALITRERA EN TARAPACÁ
}

\author{
THE BEGINNINGS OF THE NITRATE INDUSTRY IN TARAPACÁ
}

\author{
Carlos Donoso Rojas ${ }^{1}$
}

\begin{abstract}
Nuestro estudio busca complementar investigaciones relativas a los mecanismos de producción y comercialización del salitre en el período que antecede al año 1830. En funciones desde el último cuarto del siglo XVIII, la actividad afrontó la creciente demanda (consecuente de la diversificación que experimentaba el uso de nitrato) con un bajo nivel de desarrollo técnico, un modelo que permaneció invariable durante décadas. Sin inversiones tecnológicas o científicas orientadas a un provecho eficiente del caliche, la industria suplió la innovación con el incremento continuo de su oferta laboral, que redundó en la calidad y valor final del producto. La precariedad de una iniciativa que privilegió el trabajo manual por sobre inversiones de capital y la tecnificación de las faenas, debe ser entendida en el contexto de su época, donde el margen de rentabilidad neta del negocio era bajo, al que se sumaba un porvenir incierto, el temprano surgimiento de oligopolios y la inestabilidad política del Perú en los años posteriores a la independencia.
\end{abstract}

Palabras claves: salitre, Tarapacá, oligopolio, Huantajaya, fiscalidad.

Our research seeks to complement existing information on the mechanisms of production and commercialization of saltpeter in the period preceding the year 1830. Starting in the last quarter of the eighteenth century, this activity faced the increasing demand (as a consequence of the diversification of the use of nitrate) with a low level of technical development, a model that remained unchanged for decades. During the period under study, since there was no technological or scientific investment aimed at an efficient exploitation of nitrate, the industry replaced innovation with an expansion of labor supply, which had an impact on the quality and final value of the product.

The precariousness of an initiative that favored manual labor over technological innovation should be understood in the context of its time, where the net profitability margin of the business was low, to which must be added an uncertain future, the early consolidation of oligopolies and the political instability of Peru in the years after its independence.

Key words: Nitrate, Tarapacá, oligopolies, Huantajaya, taxation.

La explotación del salitre determinó, de un modo absoluto, la evolución social y política de Tarapacá, aun percibiendo de modo marginal sus beneficios pecuniarios. La historiografía chilena reconoce su trascendencia, cimentándola en la premisa de su impacto en la remodelación financiera del Estado desde los inicios de la guerra contra Perú y Bolivia. La historia previa, en contraste, ha sido menos atendida, centrándose en los procesos políticos asociados al frustrado monopolio peruano, vinculando su relevancia a iniciativas impulsadas en Chile sobre propiedad y políticas tributarias, una vez ratificada la conquista de la provincia (Donoso 2014:63-101; González 2012 y 2013).

Visto en perspectiva, el paradigma del cambio de modelos arcaicos de explotación a otros con estándares industriales ocurrió solo cuando el Estado peruano definió su posición frente a ella, regulando la adjudicación de terrenos, y reservándose su posterior usufructo. El período anterior a 1830, entendido a partir de referencias aisladas y bases documentales dispersas, se entiende en cambio como un proceso histórico menor, donde la falta de regulación tiene equivalencia simétrica a iniciativas condicionadas por sistemas de producción y comercio ineficientes.

Esa escasez de antecedentes es la que ha supuesto la existencia de una tardía modernización en Tarapacá solo pocos años antes de la conquista chilena. Su inicio, de hecho, se ha legitimado en torno a una efeméride, justificada en el interés por hacerla coincidir con el esperado resurgimiento de la industria, tras la creación de la Compañía de Salitres de Chile, en 1930. El maniqueísmo derivado del aparente despacho fundacional de 18.700 quintales (860 toneladas), propuesto por Roberto Hernández, fue reforzado por Bermúdez para señalar el comienzo de su exportación a Europa (Bermúdez 1963:106; Hernández 1930:30).

\footnotetext{
${ }^{1}$ Departamento de Ciencias Históricas y Geográficas, Universidad de Tarapacá. 18 de septiembre 2222. Arica, Chile. cdonoso@uta.cl
} 
Las obras de ambos investigadores, de uso imprescindible, si bien indagan en los años previos al hito inicial, han contribuido a reducir a un mero compendio de datos la historia previa a 1830, sin precisar el origen de las fuentes utilizadas (lo que condiciona su valor). Hernández replica los datos publicados por Madueño, en uno de los escasos estudios del tema durante el período peruano (Madueño 1919:86), al tiempo que éste sigue las cifras de Paz Soldán (1877:465-466).

La nebulosa que acompaña los inicios de la producción salitrera debe contextualizarse en torno a las complejidades propias de un sector en apariencia irrelevante durante el período colonial, al menos en comparación a otras desarrolladas en Tarapacá ${ }^{1}$. El salitre, en efecto, jugó un papel secundario ante la minería argentífera, la agricultura y la pesca, que varió solo tras la promulgación de las primeras indicaciones del gobierno peruano vinculadas a su comercio. La autorización dada por el gobierno en 1827 a un desconocido Juan Alma para exportarlo, marcóel inicio de un período que acabó por posicionar los intereses del Estado sobre un recurso de importancia creciente. Ya en 1830, el ministro de Hacienda avizoraba que "las salitreras riquísimas que poseemos, y que empiezan a ser conocidas de los extranjeros, puede formar un ramo de riqueza para la nación" (Memoria 1831:25).

Sin desconocer el enorme valor de los estudios relativos a la historia económica y social del salitre, creemos que su extracción y procesamiento operó al margen del Estado al menos durante las cinco décadas previas a su arraigada referencia fundacional. En ese contexto, su desarrollo fue organizado en torno a unidades básicas de producción y un número acotado de comerciantes e intermediarios. Sin una implementación tecnológica destinada a maximizar la producción, hasta mediados de siglo se sostuvo en base a formatos proto-industriales, donde el elaborador no contemplaba márgenes de utilidad definidos en base al valor final neto, con sistemas desregulados de pesos y medidas y, en especial, que supeditó su crecimiento a la ampliación de la oferta laboral. Esta estructura definió su carácter precario, pero también garantizó su continuidad por décadas, al tiempo que determinó un proceso de transición económica regional aun por analizar. Amparados en el estrecho vínculo entre el poder económico y la influencia política, reconocidos mineros de Huantajaya aparecen, desde fines del siglo XVIII, vinculados a su explotación, en tiempos en que la decadencia de ese mineral era evidente.

Si bien las minas de salitre del virreinato peruano, por su importancia estratégica para la fabricación de pólvora, fueron declaradas propiedad real en 1571, la corona hasta no definió sino hasta 1787 una política respecto a qué hacer con su elaboración y comercio, quizá por la frustrada experiencia de su estanco en España (Sánchez 1985). Después de reiterados intentos por traspasar su administración a particulares, la monarquía revalidó ese año sus derechos, en el contexto de una reforma mayor que, al concentrar la venta de insumos esenciales como azogue, tabaco y pólvora, buscó simplificar los procesos de cobro y recaudación de impuestos, a la par con la necesaria modernización de los sistemas productivos y la protección de los intereses financieros reales.

El monopolio tuvo en Tarapacá un efecto limitado porque la inhibición de las faenas mineras, consecuencia del irregular abastecimiento de elementos estancados como el azogue, se confrontó con la vulneración sistemática de las normas restrictivas. La solicitud de José Mamani a las autoridades, en 1782, para adjudicarse unos "montes de salitre" ubicados camino a Huantajaya, estaba en directa relación con lo que definía como "la muy necesaria demanda del elemento para el laboreo de las minas"2. La referencia, asociada a la necesidad de explosivos en labores mineras, parece un intento por atender, por vías lícitas, una demanda suplida hasta entonces por paradas e instalaciones clandestinas, tolerada por las propias autoridades como una solución provisoria a la falta de provisión fiscal ${ }^{3}$.

Como ha señalado Rosenblitt (2014:35-66), la repercusión de iniciativas estatales del período no logró modificar una estructura económica orientada al mercado regional. Un informe del visitador de Hacienda, en 1785, reconocía el fracaso del monopolio de venta de la pólvora en Tarapacá, donde el insumo se vendía con libertad y a un costo menor. A su juicio, el error estaba en que tanto el azufre como el salitre nunca fueron estancados y la prohibición a su producción y comercio no se fiscalizó de la forma debida (O.S. 1872:408).

La fabricación de explosivos constituía un acto de desacato a la autoridad real, tanto como la estricta prohibición de enseñar el arte de fabricarlo a la población indígena. Es frecuente, sin embargo, encontrar en testamentos o en causas judiciales coloniales relatos de personas que se declaraban polvoreros, fuegueros $u$ olleros, oficios derivados de los métodos de refinación utilizados en la elaboración de pólvora. En tiempos de la sublevación de Tupac Amaru, en 1781, Melchor Berrío, natural de Matilla y acusado de participar en movimientos subversivos en el interior, fue identificado como "cohetero" y trasladado en aislamiento a la isla Serrano, entonces una importante de reserva de guano frente a Iquique, con la recomendación de asegurarlo "para que no haga pólvora o componga la que ahí hubiese"4.

Berrío era operario de un importante centro de refinamiento próximo a Pica, propiedad de Matías González de Cossio, un prominente personaje del Tarapacá colonial. Este, a su vez, lo había adquirido 
de Ambrosio de Morales en 1777, adaptando antiguos fondos destinados al beneficio de la plata de Huantajaya. En 1799, un visitador de minas registró en el interior de Tarapacá cinco paradas activas de producción de caliche ${ }^{5}$.

\section{Salitre en el Ocaso del Ciclo Colonial}

La interrogante respecto a si durante el siglo XVIII el salitre pudo ser utilizado en labores no asociadas a la elaboración de explosivos sigue abierta. Hasta entonces, la nula innovación en los sistemas extractivos y de procesamiento del caliche tuvo como consecuencia marginal (pero no menos relevante) la elaboración de nitrato de calidad disímil, lo que debió redundar en usos y precios diferenciados. Una referencia de la existencia de indicadores de calidad en su producción data de septiembre de 1830, cuando la Administración de Rentas de Arica, al no disponer de normativas asociadas a unidades de peso ni elementos jurídicos para determinar la tributación a pagar por el mineral, optó por aplicar una escala de valores a partir de los tres tipos de "cocimientos" utilizados en Tarapacá para determinar su grado de pureza ${ }^{6}$.

Si bien la clasificación cualitativa fue desechada, la tipificación es sugerente. Crozier ha demostrado que ya a inicios del siglo XVII europeo, el consumo del nitrato era significativo, y que su uso como fertilizante fue entonces percibido, en Alemania, como la solución a un prolongado período de crisis agrícola (Crozier 1997:54-55). Suponer su uso con fines similares en América es factible, aunque no existen estudios que refieran su empleo específico en estas materias. Una antigua tesis doctoral española, orientada a analizar el origen y composición química del recurso, señala su empleo en faenas agrícolas en Perú desde el siglo XVII, pero no alude a sus fuentes de información (de Fiestas 1923:18). Mucho más concreto, un documento conservado en la Biblioteca Nacional del Perú, que data de 1612, refiere al caso de una mujer, dueña de haciendas en Ica, quien denunció a un lugarteniente por su responsabilidad en la pérdida de parte importante de su producción agrícola, porque, como señala, "no le echó salitre en sus solares" ". Se trata de una referencia excepcional que puede no referir al nitrato de Tarapacá, existiendo depósitos próximos, en Trujillo e Ica. Estos, no obstante, por su alta alcalinidad eran empleados solo en la elaboración de pólvora.

Las primeras evidencias de exportación de nitrato se relacionan con el aludido González de Cossio, quien en 1804 obtuvo un préstamo del comerciante limeño Lorenzo Robledo para explotar yacimientos salitrales de Tarapacá con destino a Chile, en sociedad con Matías de la Fuente y Sebastián de Ugarrisa. La sociedad comprometió el despacho de entre doscientos $\mathrm{y}$ trescientos quintales de nitrato anuales, montos que no pudieron cumplir, argumentando que "las producciones actuales hasta ahora son tan escasas que apenas costean los gastos".

Los envíos fueron regularizados en 1806 y se mantuvieron tras la muerte de González de Cossio dos años después, cuando los restantes socios informaron a Robledo que trabajaban en un nuevo proceso para maximizar la pureza del salitre, pensando en su mayor consumo 9 . La aseveración era efectiva: en julio de 1809, el periódico Minerva Peruana, publicado en Lima, informaba la existencia al interior de la provincia de Tarapacá "de cómo treinta leguas de nitrato de soda", las que ya habían sido explotadas por la misma sociedad que intentaba separar la sosa para convertirlo en nitrato de potasa, con ayuda del químico Tadeo Haenke (Billinghurst 1889:11).

Ese año, Ugarrisa y de la Fuente enviaron 350 quintales con destino a Chile, donde el mineral era conocido como "tierra nitrosa de las costas del Perú", habilitando en Iquique algunas bodegas para su custodia (Mendiburu 1880:225). Parte de la producción calichera de Tarapacá tuvo por destino la ciudad de Concepción, donde a inicios de siglo se había establecido una fábrica de jabón que utilizaba nitrato. Del compromiso inicial de envíos no superiores a trescientos quintales al año, en 1809 Billinghurst señala que en el período marzo 1812-enero 1813, los despachos se incrementaron a 22.723 quintales (Billinghurst 1889:12). Roberto Hernández (1930:15), aludiendo al mismo período apuntado por Billinghurst, señala una producción de 23.160 quintales, proyectando una elaboración tentativa de 70 mil cada uno de esos años. Sus cifras se aproximan a las de Mariano Rivero, quien en 1821 destacó la existencia en Iquique de más de sesenta mil quintales, purificados por disolución y cristalización, listos para su embarque (Rivero 1857:6). En 1825, el testimonio recogido por una publicación científica alemana señalaba una producción de 935 toneladas en Tarapacá, alrededor de 20.300 quintales, aunque sin precisar el período (citado en Crozier 1997:126).

El aumento de los despachos puede explicarse por el mejor aprovechamiento del caliche, por el aumento de la demanda y, fundamentalmente, por la creciente disponibilidad de medios de transporte. El británico John Blake, que recorrió Tarapacá a inicios de los años treinta, recordaba como una característica de la zona el gran número de animales de carga muertos en la pampa, los que eran apilados como señales de orientación en las rutas hacia el interior (Blake 1843:7). Impulsado por comerciantes establecidos en Arica, la creciente dotación de animales de carga tendrá una incidencia clave. Tomando como referencia una negociación para el acarreo de salitre de 1832, una mula podía soportar una carga de 13 arrobas, equivalentes a 149,5 kilos 
(3,25 quintales). Una recua de 31 animales podía cubrir una distancia de 15 leguas (alrededor de 72 kilómetros) 48 veces al año, transportando en cada viaje 4.836 quintales (Rosenblitt 2010:99).

El dato anterior es interesante, pues permite dimensionar una actividad que, pese al alza sostenida de su exportación y las mejoras introducidas, veía condicionado su crecimiento tanto a la preservación de técnicas rudimentarias de elaboración como a los problemas de movilidad del mineral. Frente a un eventual incremento en la demanda, la habilitación progresiva de nuevos medios de transporte permitió sostenerelmercado, perotambién explicasuestancamiento posterior por los crecientes costos asociados.

La reducción de márgenes de utilidades derivado del encarecimiento de la producción, condicionados por el valor del transporte, tuvo directa incidencia sobre su reducido comercio a inicios de siglo, contrayéndose a niveles mínimos a partir de 1814, cuando las autoridades virreinales declararon la interdicción comercial con Chile. Los puertos de Tarapacá fueron abandonados (en noviembre de 1814 Iquique y Huantajaya eran custodiados por solo treinta soldados) ${ }^{10}$, lo que favoreció la proliferación de corsos y contrabandistas en las costas provinciales. Retiradas las fuerzas al interior, debieron hacer frente a la insurrección militar liderada por Julián Peñaranda para combatir las tropas leales a la corona en el Alto Perú. Tras ocupar la capital provincial, Peñaranda prosiguió la persecución de enemigos, destruyendo, a modo de represalia, las instalaciones de tres paradas próximas a Negreiros, que pertenecían al último subdelegado realista de Tarapacá, Manuel Almonte (Lanas 2016:409-432; Ugarte 1932:15) ${ }^{11}$.

El levantamiento contra el dominio hispano no fue acompañado en Tarapacá de una ocupación efectiva de las fuerzas independentistas. Por el contrario, Iquique, por su cercanía a Huantajaya, se transformó en el centro del tráfico ilícito de mercancías de la provincia, mientras que Pisagua se convertía en punto de embarque clandestino del salitre extraído en las inmediaciones de Negreiros. En 1819, los hermanos Pascual y Francisco Flores, comerciantes con residencia de Iquique, fueron acusados de contrabandear caliche a Chile durante la vigencia del bloqueo, logrando forjar una riqueza importante. Francisco llegó a ser dueño de "una de las más destacables construcciones del puerto", mientras Pascual, un reconocido republicano, tuvo activa participación en el movimiento revolucionario ${ }^{12}$.

La irrupción de las guerras de independencia en Tarapacá afectó la continuidad de la producción, pero no los intentos por difundir en mercados externos sus propiedades y beneficios. A fines de la década, Pedro Fuente, originario de Tarapacá y asentado en Concepción para trabajar en la purificación del caliche, dio a Mariano Rivero una porción de nitrato de soda.
Una vez establecido en Europa, distribuyó parte de la muestra entre mineralogistas para verificar su composición, al tiempo que demostró, sin mayor éxito, sus propiedades en áreas tan diversas como la industria química y la agricultura (Billinghurst 1889:13).

\section{La Post-Independencia en Tarapacá}

La independencia boliviana y el asentamiento de la institucionalidad republicana en el Perú supuso en Tarapacá el restablecimiento del orden y la reactivación de una económica deprimida, evidenciada en el registro de solo 22 individuos en la provincia con capacidad financiera para ser validados como contribuyentes en $1825^{13}$.

La recuperación tuvo como principal impulsor a Ramón Castilla, destacado militar de las guerras de independencia y futuro presidente del Perú durante dos períodos. Originario de Tarapacá, tras su designación como subprefecto provincial en 1825, Castilla visualizó el necesario giro de la economía regional desde la minería de plata a la explotación salitrera, tras el inminente agotamiento de Huantajaya, solicitando a George Smith recorrer y cartografiar Tarapacá.

Smith, entonces empleado en la casa consignataria del británico Hogdson en Iquique, inició su trabajo en compañía de Bollaert, culminando su labor en 1827. Si bien el reconocimiento de la región respondió a la necesidad de definir los límites con Bolivia para solucionar cuestiones legales entre comunidades indígenas del interior, la carta elaborada por Bollaert y Smith se transformó en la más exhaustiva representación de la provincia hasta entonces realizada, dando énfasis al trazado de rutas camineras y a la ubicación de yacimientos minerales, incluyendo, por cierto, los depósitos salitrales. En el corto plazo, el detallado catastro fue clave para cuantificar las perspectivas económicas de Tarapacá, generando en los años venideros condiciones administrativas y tributarias favorables para la inversión privada y los intereses fiscales.

El excepcional trabajo de Bollaert y Smith se enmarcó en una poco conocida iniciativa de las autoridades centrales por practicar el reconocimiento exhaustivo del territorio, con el objetivo de lograr una estimación de la disponibilidad de recursos en explotación del país, con miras a la creación del primer presupuesto republicano para el año 1827. A inicios de ese año, el prefecto de Arequipa designó al vecino Mariano Flores como Visitador General de Hacienda de Tarapacá, con la misión de realizar un catastro de las labores productivas de la provincia, y sugerir medidas que garantizasen una tributación eficiente. Flores, propietario de estacas en Huantajaya, destacó en su informe la pobreza de la provincia, aduciendo que era 
el contrabando, y no la falta de producción, el principal problema a resolver. A su juicio, complementario al establecimiento de mecanismos de fiscalización en la costa, resultaba esencial reconocer y dar un estatus jurídico a los puertos de Tarapacá. Flores puso especial énfasis en Iquique, el de mayor movimiento de la región y que se encontraba abandonado por las autoridades, indicando que "pueden con franqueza y sin riesgo arribar buques y espeder [sic] sus artículos comerciales sin contribuir ningún derecho al Estado" $" 14$.

La propuesta de Flores, sin mayores modificaciones, fue presentada en 1828 al Congreso por Manuel Cuadros, diputado provincial con intereses en la extracción de guano en la isla Serrano. La iniciativa sugería la apertura de Iquique como puerto mayor, "aunque nofuese más que por la posibilidad de despachar por allí el mineral que se explota", refiriendo a la plata bruta, mineral sometido al pago de una importante carga impositiva en el Reglamento de Comercio de $1826^{15}$. Llama la atención que el rechazo al cambio de categoría fuese argumentado en la imposibilidad de establecer en Iquique, en el breve plazo, un sistema de administración que regulase la internación de mercancías y previniese la descapitalización.

Sin perjuicio de que Tarapacá formase en ese momento parte de una negociación iniciada entre los gobiernos peruano y boliviano, que contemplaba su eventual cesión a Bolivia (Ortiz de Zeballos 1956:3539), la negativa pudo justificarse por la lejanía y las condiciones de vida de la región. En septiembre de 1827, un informe presentado al gobierno por el Comandante General de Marina, señalaba que el cargo de capitán de puerto en Iquique estaba vacante por años, sin que a la fecha existiese registro alguno del movimiento portuario. En 1830, cuando las exportaciones reguladas de salitre se habían iniciado, el prefecto de Arequipa comunicaba al ministro de Hacienda la dificultad para completar las plazas administrativas, por lo poco atractivo que representaba trabajar en el servicio público en Tarapacá, "provincia extensa, de malos caminos, escasa de víveres, muy escasos estos y muy malo el temperamento"16.

Para efectos comerciales, Iquique fue designado puerto menor en octubre de 1827, una condición que, aunque implicaba la creación formal de resguardos, suponía también una serie de restricciones que limitaba un tráfico hasta entonces informal. El Reglamento de Comercio forzaba a las embarcaciones a fondear en ellos solo una vez autorizado en la aduana del puerto mayor respectivo, lo que facilitaba el control portuario pero que, al mismo tiempo, se transformaba en un estímulo al contrabando. La administración comercial de Iquique se complejizaba por su dependencia de la aduana de Arica, vínculo que solo se formalizó en 1830, dependiendo hasta esa fecha de las autoridades portuarias de Islay, donde las naves debían efectuar los registros correspondientes ${ }^{17}$.

La lejanía de los puertos mayores se constituyó en una traba para la eventual recuperación del mineral de Huantajaya y el despegue de la exportación salitrera, pese a las políticas de fomento propuestas por los gobiernos del período para incentivar la producción minera, las que iban desde la creación de callanas próximas a yacimientos en explotación hasta la exclusión del pago de contribuciones a quienes invirtiesen en nuevos emprendimientos mineros ${ }^{18}$.

Es difícil precisar si las medidas tuvieron un impacto real en la minería tarapaqueña. Aunque el padrón de contribuyentes de la región creció a 192 individuos a fines de 1827, el incremento parece más tener relación con el fin de las hostilidades en la zona, que con la aplicación efectiva de los estímulos gubernamentales. Un factor complementario tiene relación con el papel jugado por las propias autoridades políticas. En un informe enviado a Londres desde Lima a inicios de 1827, el cónsul británico denunciaba que la totalidad de los poderes civiles del Perú se regía "por el principio universal de corrupción", institucionalizando la impunidad ante el contrabando y el soborno (Bonilla 1975:22). Tarapacá no era la excepción, a juzgar por los reiterados casos de irregularidades que, desde inicios de la república, involucraron a reconocidos productores que ejercían funciones públicas paralelas, asociados a desfalcos de fondos públicos y participación en el comercio ilegal $^{19}$. A su llegada a Iquique en 1830 , Darwin destacó en su diario de viaje que sus habitantes supusieron, con el arribo del Beagle, la llegada de una comitiva recolectora de contribuciones forzosas, a las que el pueblo se habría visto sometida con recurrencia los convulsionados años posteriores a la independencia (Darwin 1945:430).

\section{Inversiones Privadas e Intereses Públicos}

Al constituirse en república, Perú mantuvo en vigencia la normativa hispana en materias mineras, adecuando las Reales Ordenanzas de Minería de Nueva España de 1783, dejando al Estado como propietario de los recursos mineros, con amplias facultades para adjudicar a particulares su explotación. En la práctica, sin embargo, el usufructo no fue regulado de forma efectiva, lo que facilitó la concentración de propiedades y la especulación sobre los terrenos explotables (Errázuriz 1913:7).

La solicitud presentada al gobierno en 1827 por un hasta hoy desconocido Juan Alma marcó el inicio de una nueva etapa en la relación entre los productores con el Estado peruano, al solicitar expresa autorización al gobierno para exportar salitre refinado desde mayo de $1828^{20}$. El caso es interesante, no solo porque se 
transforma en la primera referencia que vincula la explotación del recurso y el Estado republicano, sino porque formalizó su comercio de acuerdo a parámetros fiscales. A partir de la autorización a Alma, quedó sometido al pago de una arancel general (cuatro centavos por quintal) y a la estricta regulación portuaria, limitando su zarpe a los destinos informados solo desde puertos mayores, donde se haría el registro y cobro del tributo respectivo ${ }^{21}$.

La solicitud fue presentada poco tiempo después que George Smith comprase la parada La Noria al francés Héctor Bacque, por lo que es probable que detrás de Alma estuviese la intención de consolidar un monopolio, al menos temporal.

El reconocimiento, cuyos alcances económicos desconocemos, tiene una consecuencia marginal pero no menos relevante, al crear el precedente legal básico de la propiedad fiscal del recurso. En adelante, productores y comerciantes salitreros debían seguir el camino jurídico iniciado por Alma, exponiéndose a ser sancionados por ejercer contrabando. Dos de ellos, Bartolomé Morales de Loayza y Santiago Zavala fueron sometidos a juicio por esa causa. Morales en su defensa, sugirió que el permiso constituía la intervención de una iniciativa que "desde siempre se practicó de forma libre", y que los principales perjudicados serían los pequeños elaboradores, con quienes tenía lazos comerciales directos ${ }^{22}$. Santiago Zavala, por su parte, definió como inconcebible el pago de una tributación, aunque no le resultaba extraña, teniendo en cuenta la entrega de una cantidad significativa de terrenos salitrales en Tarapacá a extranjeros, apoyados en derechos de explotación otorgados en Lima, sin atender los intereses de productores y consignatarios con mayor antigüedad ${ }^{23}$.

El alegato de Morales deja entrever una relación de dependencia de dueños de pequeñas oficinas o paradas, expresada en la venta de su producción a propietarios de otras, con mayor capacidad de compra. Más destacable es el caso de Zavala, para quien la libre explotación se confrontó a la aplicación de un marco regulatorio que escapaba a las prácticas consuetudinarias, en especial a aquellas relacionadas con su concepción de propiedad pública. La molestia de Zavala por la pérdida del establishment también simboliza la pérdida de poder de la antigua elite, relegada ante la llegada de una nueva generación de salitreros, quienes, además de apropiarse de los principales suelos, rivalizaron por atender a los mismos mercados. Tanto Morales como Zavala se declaraban solo como productores, por lo que la continuidad de sus labores no se relacionaba con la demanda del mineral, cuyo flujo era controlado por mercaderes y, después de 1821 , por las casas comerciales de capitales extranjeros instaladas en Iquique o Arica.
Zavala acertaba en su alegato al señalar que el permiso a Alma fue otorgado en un año especialmente convulsionado en la vida política del Perú (solo en 1827 hubo cuatro gobiernos), sin perjuicio que el trasfondo de sus argumentos apuntase a validar su propia participación en el negocio. Zabala, de hecho, además de sus intereses salitreros, era propietario de estacas en Huantajaya y presidía el gremio de mineros de Tarapacá. En tal condición, en 1829 solicitó al gobierno la apertura de registros para el despacho en Iquique y no en el puerto de Islay, además de habilitar los puertos de Mejillones y Pisagua para su embarque ${ }^{24}$. El reconocimiento a la autoridad política forzó la creación de instancias para negociar y confrontar intereses en torno al salitre. De este modo, a inicios de 1830 obtuvieron aprobación para trasladar el nitrato desde ambas caletas, con el fin de cargarlo y conducirlo hasta Iquique, en donde podía reembarcarse, despachándose los registros hacia Arica $^{25}$.

Menos favorable fue la respuesta a la decisión del gobierno, en abril de 1831, de iniciar el cobro de gravámenes sobre el salitre sin indicar su trasfondo legal, los montos exigibles, y las unidades de peso a utilizar, dejando en manos del administrador de rentas de Arica una estimación de su valor, de acuerdo a "la utilidad que reporte su industria, no debiendo gravarse aquella como un gravamen [sic] capaz de paralizar una especulación lucrativa" (CLDO 1837 IV:30). El administrador dispuso que fuese gravado de acuerdo al grado de pureza declarado por los propios productores, diferenciando tres grados de calidad de acuerdo a su técnica de elaboración ${ }^{26}$.

El cobro fue rechazado por un grupo de productores, quienes hicieron ver su ilegalidad, por no estar listado entre los minerales afectos al pago de contribuciones del Reglamento de Comercio. Una recusación judicial interpuesta ante el ministerio de Hacienda por un grupo de mineros (entre los que destacaba Santiago Zavala, José de la Fuente y Jorge Smith), permitió dilatar el cobro hasta octubre de 1832, periodo en el cual la explotación y exportación de salitre fue liberado ${ }^{27}$.

El impuesto del cuatro por ciento sobre un avalúo, formalizado a fines de 1832 , tuvo un trasfondo singular, al constituirse en un monto acordado entre las autoridades políticas y una contraparte a quienes la norma definía simplemente como "salitreros" (CLDO 1837 IV:374). Sin distinguir entre productores y comerciantes, es probable que la opinión de estos últimos tuviese mayor injerencia, considerando que, salvo casos puntuales, la venta del mineral se realizaba a través de casas consignatarias. La creación de un tributo implicó, en la práctica, traspasar a privados los costos de un sistema aduanero precario, pero que garantizaba su continuidad. El cobro, al ser presentado como una 
subvención que permitía financiar un resguardo militar destinado a prevenir el contrabando en las caletas aledañas, se trasformó en una garantía orientada a facilitar el flujo expedito de las exportaciones.

La justificación del cobro (forzado con la sutil advertencia de cerrarlo en caso de no contar con el financiamiento de privados), dio al negocio salitrero un impulso relevante, reflejado en el incremento de sus envíos al exterior, favorecido con la promulgación de un nuevo Reglamento de Comercio en 1833, que autorizó a los buques de bandera peruana a viajar en lastre a Iquique para transportarlo, con exclusión de plata y oro en pasta o amonedado (CLDO 1837 IV:371372). El impacto de esta medida se refleja en los totales exportados: mientras en 1832 fueron despachados por Iquique 52.500 quintales, en 1834 la cantidad se incrementó a 147.800 (Hernández 1930:30).

\section{Mecanismos de Producción y Relaciones Laborales}

El alza en los envíos de salitre desde inicios de los años treinta, registrados desde entonces con aparente rigurosidad por las autoridades tributarias, alude a una dinámica económica en ascenso que, sin embargo, resulta difícil de cuantificar con precisión. El aumento tampoco explica las condiciones en las que se producía, y de qué forma se adaptó a un modelo de desarrollo comercial determinado por el consumo ascendente y el advenimiento de la economía monetaria.

Pese a que desde 1830 la internación al Perú de equipos con fines industriales estuvo exenta del pago de contribuciones, no existen noticias de mejoras en técnicas de producción posteriores al referido aporte de Tadeo Haenke en 1808. Los primeros atisbos de innovación aparecen recién a fines de esa década, cuando el francés Alejandro Cochet, asociado con Smith, instaló en La Tirana una parada para producir nitrato de potasa con salitre sódico, a través de un sistema de procesamiento que le llevó a formar un rústico laboratorio químico en Iquique ${ }^{28}$. Aunque algunos autores lo presentan como un posible timador (Bermúdez 1963:131; Crozier 1993:154), Cochet reclamó el reconocimiento de ser él quien dio a conocer las propiedades del mineral en Europa, correspondiendo a su mérito el valor y cuantía de exportaciones (Cochet 1841:20 y 1847:s.p.).

La propuesta del francés, al margen de las desventuras del caso, parece una innovación excepcional que solo fue superada en 1853 por la implementación del sistema de vapor de Pedro Gamboni, el que producía a menor costo energético, obteniendo salitre con un mayor grado de pureza. Sin ser una creación revolucionaria, el sistema marcó un avance cualitativo determinante para un procesamiento más eficiente del mineral a mediados de siglo.
Como una consecuencia marginal, la invención de Gamboni dejó en evidencia el mayor problema de la incipiente industria: los altos costos de producción derivados del valor de los insumos, lo que tenía incidencia en la calidad y cantidad producida. En 1853, Pedro King solicitó al gobierno chileno autorización para instalar paradas en Lota, puerto próximo a Concepción desde el que se despachaba parte del carbón empleado en las faenas. King argumentaba que era más rentable elaborar salitre en ese lugar enviando el caliche desde Tarapacá que comprándolo refinado (Caliche I 1919:25).

Desconocemos si la solicitud de King fue acogida. La petición, sin embargo, plantea interrogantes respecto al beneficio económico neto generado, asumiendo que los costos asociados a técnicas de producción básicas, sumado a los de transporte, encarecían el valor final de un insumo de demanda creciente, pero de valor oscilante. Hotelling (1931), al intentar explicar las variables que determinan el precio final de los recursos no renovables, sostuvo que la conversión de los depósitos naturales a bien rentable debía contemplar el aumento de su valor de equilibrio, al mismo ritmo que la ejecución de inversiones proporcionales a la estimación de la demanda.

Considerando que el valor de un depósito era también el valor presente de sus ventas futuras, Hotelling afirmaba que los productores debían aspirar a que el precio neto del mineral aumentase al mismo ritmo que su demanda, tras deducir los costes de extracción, atendiendo factores como su escasez y explotación racional del recurso. Si la industria minera era competitiva, el precio neto (valor que cubría los costos asociados y dejaba el margen de rentabilidad estimado) sería igual al precio de mercado, menos el coste marginal de extracción. En contraste, si operaba en condiciones de costos constantes, el precio neto debía ser igual al precio de mercado, menos los costes unitarios de extracción, es decir, igual al margen de beneficio.

Unade las críticas recurrentes alateoría de Hotelling refiere a la irrelevancia dada a las externalidades posibles de visualizar en el proceso, como los problemas derivados del surgimiento de dinámicas inestables en los precios, o la demanda especulativa. Suponiendo, para el período en estudio, la existencia de precios constantes y un aumento sostenido de las exportaciones, el incremento en la demanda tuvo que ser cubierta sin mediar cambios tecnológicos ni inversiones relevantes que permitieran estimar el costo constante de su elaboración, supliendo estos factores con una alta oferta de trabajo caracterizada por la precariedad salarial. Este modelo de relaciones laborales y de producción se mantuvo por décadas, causando un efecto adverso en la industria, al quitarle urgencia a la implementación de 
cambios tecnológicos, privilegiando la asimilación de mano de obra de bajo costo. La nula innovación en los sistemas de extracción y procesamiento del caliche tuvo como resultado marginal (pero no menos relevante) la elaboración de salitre de calidad disímil, lo que debió redundar en el precio final del producto.

La ocupación manual sostenida con salarios reducidos, además de pauperizar las condiciones de vida, estaba destinada a perdurar poco tiempo debido a la continua migración a Tarapacá, de chilenos principalmente. De tener poco más de mil habitantes en 1830, la provincia incrementó su población a 4.593 habitantes en 1845. Del total señalado, más del 82 por ciento residía en el interior (Durand 1975:115-200).

La fragilidad estructural del salitre debe también contextualizarse en la evolución política de la República peruana de la postguerra, donde la competencia y la calidad de las políticas gubernamentales quedaban supeditadas a luchas entre facciones y la pervivencia de prácticas contrarias a la consolidación del Estado. Entre 1834 y 1877 , seis de los siete principales quiebres institucionales de la república se desarrollaron en Tarapacá. La revolución de 1834, que enfrentó a Agustín Gamarra y José Luis Orbegoso, fue la primera de ellas, afectó la producción al redestinarse el uso de instalaciones a la fabricación de pólvora, y ser sometidos, tanto propietarios como trabajadores, a exacciones y reclutamientos forzosos. Como en tiempos de las guerras de independencia, la presión impulsó a muchos productores a abandonar la provincia, indiferente de la opción política que enfrentasen. Santiago Zavala, convertido esta vez en subprefecto de Tarapacá y leal al mando de Gamarra, en junio de 1834 informaba al gobierno del fracaso por conseguir un empréstito entre los propietarios locales, "tanto por su escaso número como por su manifiesta pobreza". Apremiado por la escasez de circulante, y con la urgente necesidad de costear el abastecimiento y transporte de tropas, Zavala logró reunir solo cuatro recuas de mulas y 444 pesos, tomando por la fuerza fondos de la capitanía de puerto, tenencia de aduana y de la alcaldía de Huantajaya ${ }^{29}$.

Es interesante constatar, sin embargo, que la merma en la producción no tuvo impacto alguno con los montos registrados de exportación. De acuerdo a las cifras de Paz Soldán, el mismo año en que Zavala advertía de la ruina de Tarapacá, la cantidad exportada superó los 147 mil quintales, casi dos terceras partes más de lo despachado el año previo. En agosto de 1834 , en momentos en que aún regía el bloqueo al movimiento portuario, el administrador de Iquique informaba que a diario arribaban cuatro o más naves a cargarlo o a regularizar su carga proveniente de Mejillones y Pisagua, teniendo un tiempo de espera en la bahía de entre cuarenta y sesenta días ${ }^{30}$.

Lo que parece un sinsentido, tomando en cuenta el mencionado abandono de la producción y el incremento de la exportación, no fue sino consecuencia de un modelo de relaciones económicas precario, que al mismo tiempo definió un modelo de negocios excepcional. Por un lado, un núcleo de productores logró configurar un verdadero oligopolio que replicó en el salitre el control que antes tuvo sobre Huantajaya. Por otro, residía en la provincia un pequeño grupo de comerciantes integrado preferentemente por extranjeros, quienes tenían reservas acumuladas y lo vendían sin mayores restricciones, amparados en su condición de ciudadanos neutrales (Documentos 1839:4). Pequeños y medianos elaboradores, como José Basilio Carpio, Esteban García, Manuel Flores y Mariano Loayza, entre otros, optaban por venderlo directamente a casas consignatarias ${ }^{31}$.

William Bollaert señala que solo en 1831 se exportaron a Gran Bretaña 240 mil toneladas, la mayor parte producida en las instalaciones de Jorge Smith (Crozier 1997:57-58). Aunque la cifra parece elevada, deja entrever el predominio del británico, que inició su trayectoria como funcionario de la Casa Hogdson y, luego, como elaborador, explotando las oficinas La Peña y Colombia. Tiempo después crearía la sociedad Smith y Paterson, siendo quizá una de las excepciones al comerciar su producción y, al mismo tiempo, operar como consignatario. En 1832 se instaló en Iquique una sucursal de Codan y Robertson, una reconocida firma comercial con casa matriz en Valparaíso. Un año después, William Wheelwright, entonces propietario del servicio de navegación entre ese puerto y Cobija, solicitó al gobierno peruano autorización para depositar hasta cincuenta mil quintales en ese puerto, sin necesidad de pasar por Arica, maderas y víveres para construir un depósito de salitre ${ }^{32}$.

La proyección comercial de Wheelwright permite apreciar las expectativas del negocio, pero también su gran paradoja. Las inversiones y mejoras tecnológicas aplicadas a su elaboración, como punto transicional hacia su mecanización, fueron posteriores al aumento de la demanda y de la consolidación del comercio como el puntal del cambio hacia modelos más eficientes de producción. La ausencia de medios de innovación (entendidos como la inserción de soluciones orientadas a maximizar la producción) y la precariedad del mercado laboral están, en el caso del salitre, directamente relacionadas.

Orientada por sistemas de producción artesanal, la explotación salitrera y el comercio asociado definió, durante el ciclo colonial, características propias y homologables hasta la segunda mitad del siglo XIX. Hasta entonces, la ausencia del sentido de propiedad privada sobre los yacimientos (expresada en las escasas inscripciones notariales registradas para usufructo particular de terrenos) configuró un desarrollo limitado al ámbito doméstico, con niveles mínimos de especialización y mercantilización. La 
producción, con una incidencia marginal sobre el mercado, estaba condicionada por la disponibilidad de insumos esenciales para la producción en su entorno inmediato (Mendels 1972:241-261; Miño 1989:793-818).

Limitada a la extracción de recursos no renovables, su precariedad estructural (propia de los mercados periféricos de la época) se relaciona con la cuantificación de los beneficios generados y con las bajas expectativas ante de la extensión temporal de la demanda. La recomendación dada en 1872 por la Junta de Ingenieros al gobierno peruano de no invertir recursos fiscales en la construcción de instalaciones portuarias en Iquique, argumentando que la producción y exportación del mineral tenía corta duración, asemeja sin variables al escepticismo demostrado en 1832 por el Administración del Tesoro Público, que, por su limitada proyección, desaconsejaba instalar controles administrativos permanentes en el lugar ${ }^{33}$.

La posterior bonanza exportadora, más que basarse en el incremento en su valor, se sostuvo en los crecientes volúmenes exportados, lo que permitió compensar los altos costos asociados a su elaboración y transporte. Sin incentivos para elaborar a una escala mayor, el retraso tecnológico de fue paralelo a la escasa innovación en los sistemas productivos, factores extensibles tanto a la inestabilidad del mercado de capitales como a la concentración de intereses en Huantajaya y minerales aledaños.

La explotación salitrera no difería de las condiciones de usufructo de otros minerales del virreinato. Centros mineros de importancia, como Cerro de Pasco o Huancavélica, hasta inicios del siglo XVIII operaron sin criterios técnicos o científicos que determinasen su calidad o maximizase su rendimiento, características propias de los laboreos artesanales de otras regiones del continente (Folchi 2001:151-156). La precariedad solo fue rota con la creciente dependencia del abastecimiento de insumos esenciales para el procesamiento mineral, como plomo y azogue, que forzó una relación estrecha entre los mineros (organizados en gremios que actuaban como medios de presión) y el Estado. Esto se tradujo en la creación de una institucionalidad financiera (por ejemplo, bancos de rescate o instituciones de fomento) proporcional a la relevancia comercial y estratégica dada por la corona o inversores privados a los minerales explotados (Figueroa 1981:33-43; Fisher 1975:30-32).

Desde el ámbito de las fuerzas productivas, la diferencia la minería metálica tradicional con la extracción y procesamiento del salitre descansaba en la estrecha relación social y económica de las paradas con su entorno próximo. Mientras en Tarapacá la explotación del nitrato se vio condicionada tanto por la rusticidad de sus faenas como por la concentración laboral de sus habitantes en el mineral de Huantajaya y los valles agrícolas del interior, en la zona central peruana la economía se organizó articulando ambas actividades, lo que facilitó la inclusión de la población campesina próxima en trabajos de explotación minera (Contreras 1988:103-137). Desde el último cuarto del siglo XVIII, además de contar con inversiones significativas de capital, la minería en los Andes centrales logró adecuar sus estrategias de producción, mutando hacia un mercado laboral libre que atrajo, de modo definitivo, a los operarios provenientes de un sector agrícola en crisis.

Mientras las transformaciones en la minería del centro virreinal determinaban un cambio espontáneo en los modelos de intercambio comercial y en la configuración demográfica del entorno, la protoindustria en Tarapacá, hasta los años posteriores a la independencia del Perú, siguió fundamentando sus operaciones en la continuidad de estructuras propias de sociedades precapitalistas, evidenciadas en el contraste entre la inserción del mineral a la economía mundial con las formas de elaboración, y las peculiares condiciones laborales asociadas a ella. El británico John Blake definió los sistemas de producción de las numerosas paradas de la pampa interior como "rudos y simples", atendidos por grupos integrados por tres o cuatro personas, donde el caliche era depositado en fondos de fierro calentados sobre un fogón. En el mismo espacio (un pequeño taller cercado por cactus y ramas), estaban las tinajas para las aguas madres y las bateas para el secado del producto diluido (Blake 1843:4-8). El relato no difiere, de modo alguno, a descripciones generales de las formas de producción realizadas décadas anteriores ${ }^{34}$ y asemeja, con exactitud asombrosa, al testimonio de Francisco Puelma (1855), quienes resalta las precarias condiciones operativas.

La falta de innovación permite también deducir dos elementos distintivos de las labores salitreras hasta mediados del siglo XIX. El primero refiere a la sobreexplotación de recursos renovables con fines energéticos, el que condicionaba la duración temporal de las faenas. Cochet en 1841, refería al agotamiento de los bosques de la zona para su uso prioritario en la elaboración de salitre, señalando que las paradas utilizaban raíces de los árboles talados, la única fuente energética disponible (Cochet 1841:19).

El segundo factor tiene relación con la percepción de riqueza y de la materialidad de la época. Tomando como referencia la descripción de bienes heredados de connotados tarapaqueños en procesos judiciales o testamentos (Aguilar y Cisternas 2013:155-195; Donoso 2006:285-330), la interrogante respecto a la magnitud comercial de la explotación del nitrato radica en la capacidad de determinar con certeza cuál 
era su beneficio neto, teniendo en cuenta que solo los costos complementarios a los ya elevados de transporte (que abarcan tanto el valor estimado de la fuerza laboral como el uso eficiente de los medios de provisión energética) encarecían el valor final de un producto de demanda creciente. En ese contexto, es pertinente preguntarse si el objetivo central de los pequeños y medianos productores (marginados de las operaciones mercantiles y enfrentados a una oferta creciente) era maximizar sus utilidades, o garantizar la continuidad de sus labores bajo mecanismos rudimentarios, limitando al mínimo la inversión. Tanto el factor rentabilidad como el de competencia no eran constituyentes del oficio en el período colonial y en la inmediata transición a la república, configurando, en cambio, una estructura arcaica pero funcional, que sobrevivió sin grandes tropiezos hasta mediados de siglo XIX.

\section{Conclusiones}

La prolongada transición salitrera desde el período colonial hacia estructuras industriales se caracterizó por la atomización de las labores en unidades aisladas, con escaso nivel de especialización, geográficamente dispersas y con una incidencia marginal sobre el valormercado de su producción. Transformada en una proto-industria ajena a los principios de protección y subsidiariedad creados por el Estado en los inicios de la república en Perú sobre sectores mineros estratégicos, las faenas basaron su expansión en el usufructo extensivo e ineficiente de los calichales, manteniendo formas de explotación inalteradas hasta avanzada la segunda mitad del siglo XIX.

Sometida a una dinámica extractiva rudimentaria, la producción salitrera creció bajo condiciones laborales excepcionales al no contar con núcleos poblados en su entorno inmediato, dependiendo de los continuos flujos migratorios a la región. Con una oferta de trabajo permanente, el incremento en la demanda por nitrato favoreció la creación de un modelo basado en la ocupación de mano de obra libre y de bajo costo, mucho tiempo antes de la abolición de los repartimientos u otras formas compulsivas de trabajo. La proletarización hizo menos apremiante las inversiones en manufactura, lo que desincentivó el desarrollo tecnológico aplicado a las faenas. Esta situación posibilitó la continuidad de las labores, por los reducidos costos de producción y el bajo riesgo asociado. La ineficiencia de los mecanismos productivos, desde el período colonial hasta mediados del siglo XIX (reproducidos con exactitud en crónicas escritas por viajeros con más de un siglo de diferencia), definirá las relaciones iniciales de intercambio, garantizando a los elaboradores no depender de las fluctuaciones de la demanda, y al intermediario de contar con una provisión regular, acorde a las exigencias del mercado.
La proto-industria salitrera no solo pervivió al paso de la monarquía a la república, sino también a la renovación de estructuras económicas globales, a las complejas crisis políticas de post independencia, y a factores naturales. La transición hacia procesos de mayor eficiencia en la producción, más que ser resultado de presiones del mercado o de innovaciones tecnológicas, fue consecuencia de la saturación del mercado laboral evidenciado a inicios de la década de 1840. El freno a su expansión y el inicio del ciclo de rendimiento decreciente en la producción fue afrontado por los gobiernos del período con la aplicación de beneficios tributarios y comerciales excepcionales para Tarapacá, las que dieron un nuevo impulso a la economía regional.

El quiebre paradigmático, sin embargo, es posterior, y se relaciona con el inicio de la construcción del ferrocarril desde Iquique al interior. La obra, convertida en la primera gran inversión tecnológica asociada al salitre, creó una cadena de valor que será determinante en la transformación de los procesos derivados de su procesamiento y venta. Hasta entonces, la dinámica operativa en torno al salitre se sustentó en relaciones económicas precarias que definieron, al mismo tiempo, un modelo de negocios excepcional forzado por la escasez del circulante y, en especial, por la paulatina adopción de nuevos sistemas de intercambio financieros. La implementación de estructuras y métodos del capitalismo moderno se expresó en la formalización de instrumentos crediticios como aval a las entregas por consignación a las casas comerciales. Su aceptación como medio válido de transacción es anterior, en al menos un par de décadas, a la implementación de una política monetaria en forma (Romero 1946:302-341).

Durante la transición a la república se consolidó en Tarapacá un núcleo de productores y comerciantes, conformando grupos reducidos que actuaron como intermediarios entre elaboradores y compradores mayoristas, acumulando importantes reservas, al tiempo que ejercían el comercio sin mayores restricciones, amparados en su condición de ciudadanos neutrales, con nexos directos con representaciones consulares y autoridades locales, asumiendo prácticas propias del período (Bonilla 1975:23-28; Webster 1839:4-14). En 1843, el Comandante de Resguardo de Iquique señalaba que era una práctica arraigada el que, tras haber embarcado dos mil quintales, los exportadores dijesen que habían despachado mil, sin que nadie pudiese acreditar lo contrario ${ }^{35}$.

Con todo, la reconfiguración material de la estructura operativa del salitre es posterior a la reorganización política del Perú, a la consolidación de procesos económicos sostenidos en flujos y transacciones de capitales, y a la propia transformación de la sociedad tarapaqueña, a través de la diversificación 
de los sectores industrial y servicios. Los mecanismos de continuidad del salitre, en contraste, se basaron en la peculiaridad de no experimentar grandes cambios en la producción, manteniendo rasgos rudimentarios que definieron la precariedad de su estructura. Esta práctica definirá, desde el período en estudio hasta avanzado el siglo XX, las relaciones de producción, pero también las de intercambio, garantizando al elaborador no depender de las fluctuaciones de la demanda, sin influencia sobre el valor de compra sugerido por el intermediario.

Agradecimientos: El presenta artículo es resultado de las investigaciones realizadas con apoyo de los proyectos FONDECYT Regular 1170738 y UTA Mayor 5748/17. Agradezco las orientaciones de los profesores Sergio González Miranda y Milton Godoy Orellana. Por supuesto, también a las asertivas críticas y sugerencias de los evaluadores.

\section{Referencias Citadas}

Aguilar, J. y P. Cisternas 2013. Pesquerías coloniales en Tarapacá, siglo XVII: mercado interno y cristianización. Allpanchis 81$82: 155-195$.

Bermúdez, O. 1963. Historia del salitre desde sus Orígenes hasta la Guerra del Pacifico. Ediciones de la Universidad de Chile, Santiago.

Billinghurst, G. 1889. Los Capitales Salitreros de Tarapacá. Imprenta de "El Progreso", Santiago.

Blake, J. 1843. Geographical and miscellaneaus notice of the province of Tarapaca. American Tour Science XLIV:4-11.

Bonilla, H. 1975. Gran Bretaña y el Perú Informes de los Cónsules Británicos: 1826-1900. Instituto de Estudios Peruanos, Lima.

Cochet, A. 1841. Disertación sobre el Guano de Iquique y su Influencia en la Formación del Nitrato de Soda de Tarapacá. Imprenta del Comercio por J.M. Monterola, Lima.

Cochet, A. 1847. Al Gobierno. Imprenta del Comercio por J.M. Monterola, Lima.

Contreras, C. 1988. Mineros y Campesinos en los Andes: Mercado Laboral y Economía Campesina en la Sierra Central. Siglo XIX. Instituto de Estudios Peruanos, Lima

Crozier, R. 1993. La industria del yodo: 1815-1915. Historia 27:141-212

Crozier, R. 1997. El salitre hasta la Guerra del Pacífico: una revisión. Historia 30:53-126.

Darwin, C. 1945 [1838]. Viaje de un Naturalista Alrededor del Mundo. Librería El Ateneo, Buenos Aires.

D’Orbigny, A. 1945 [1843]. Viaje a la América Meridional: Brasil, República de Bolivia, República del Perú, realizado de 1826 a 1833. Editorial Futuro, Buenos Aires.

Documentos que ilustran la reclamación hecha por el gobierno de S.M.B. al del Perú para procurar la reparación debida por la confiscación del bergantín británico "Ana" 1839. Imprenta de "La Opinión", Santiago.

Donoso, C. 2006. Disputas testamentarias en Tarapacá Colonial. Estudios Coloniales IV:285-330.

Donoso, C. 2014. Nacionalizar el salitre: debates iniciales sobre el control fiscal de la industria (1880-1916). Chungara Revista de Antropología Chilena 46 (1):63-101.
Durand, G. 1975. El padrón de contribuyentes de Tarapacá en 1845. Revista del Archivo General de la Nación 45:115-200.

Errázuriz, J. 1913. De la Constitución de la Propiedad Salitrera i de la Renta que ha Producido al Estado. Imprenta i Encuadernación Barcelona, Santiago.

Fiestas, B. de 1923. El Origen del Salitre. Imprenta de Francisco Román Camacho. Granada.

Figueroa, M. 1981. Bancos de fomento minero en Chile durante el siglo XVIII. Revista Chilena de Historia y Geografía 149:43-66.

Fisher, J. 1975. Silver production in the Viceroyalty of Peru 1776-1824. Hispanic American Historial Review 55 (1):25-43.

Folchi, M. 2001. La sustentabilidad de la industria de cobre en Chile: los hornos y los bosques durante el siglo XIX. Mapocho 49:149-175.

González, S. 2012. La resistencia de los tarapaqueños al monopolio salitrero peruano durante el gobierno de Manuel Pardo, desde el estanco a la expropiación (1872-1876). Chungara Revista de Antropología Chilena 44 (1):101-114.

González, S. 2013. Las políticas salitreras peruana y chilena: ¿del monopolio estatal a la libertad económica? (1873-1884). Cuadernos de Historia 38:39-77.

González, S. 2016. Matamunqui. El Ciclo de Expansión del Nitrato de Chile. La Sociedad Pampina y su Industria. RIL Editores, Santiago.

Hernández, R. 1930. El Salitre: Resumen Histórico desde su Descubrimiento y Explotación. Fisher Hermanos, Valparaíso.

Hidalgo, J. 2009. Corregidores Ilustrados en el Desierto de Arica, Tarapacá y Atacama, 1760-1780. Boletín de la Academia Chilena de la Historia 118:91-155.

Hotelling, H. 1931. The economics of exhaustible resources. The Journal of Political Economy 39 (2):137-175.

Lanas, P. 2016. El partido de Tarapacá y el extremo sur del virreinato peruano durante la revolución cuzqueña de 1814. En 1814. La Junta de Gobierno del Cuzco y el Sur Andino, editado por S. O'Phelan, pp. 409-433. Fondo Editorial de la Pontificia Universidad Católica del Perú-Instituto Francés de Estudios Andinos, Lima.

Madueño, R. 1919. La industria del salitre en el Perú antes de la guerra con Chile. El Mercurio Peruano II:85-97. 
Memoria del estado de la Hacienda en la República Peruana en fin del año de 1830, presentada al Congreso por el Ministro de Estado del despacho de Hacienda José María de Pando 1831. Imprenta de José Masías, Lima.

Memoria sobra las obras públicas del Perú presentada al Supremo Gobierno de la República por la Junta Central del Cuerpo de Ingenieros y Arquitectos del Estado. 1874. Imprenta Liberal de "El Correo del Perú", Lima.

Mendels, F. 1972. Proto-Industrialization. The first phase of the industrialization process. The Journal of Economic History 32 (1):241-261.

Mendiburu, M. 1880. Diccionario Histórico-Biográfico del Perú, Tomo IV. Imprenta de J. Francisco Solis, Lima.

Miño, M. 1989. ¿Proto-industria colonial? Historia Mexicana 38 (4):793-818.

O.S. 1872. Relaciones de los Vireyes [sic] y Audiencias que han Gobernado el Perú. Tomo 3. Imprenta y Esterotipia de M. Rivadeneyra, Madrid.

Ortiz de Zeballos, C. La misión Ortiz de Zeballos en Bolivia (18261827). Colección Archivo Diplomático Peruano. Ministerio de Relaciones Exteriores del Perú, Lima.

Paz Soldán, M. 1877. Diccionario Geográfico del Perú. Imprenta del Estado, Lima

Puelma, F. 1855. Apuntes jeológicos y jeográficos sobre la provincia de Tarapacá en el Perú. Anales de la Universidad de Chile: 665-673.

Rivero, M. 1857. Colección de Memorias Científicas, Agrícolas e Industriales Publicadas en Distintas Épocas, Imprenta de $\mathrm{H}$. Goemaere, Bruselas.

Romero, E. 1946. Historia Económica del Perú. Editorial Sudamericana, Lima.

Rosenblitt, J. 2010. El comercio tacnoariqueño durante la primera década de vida republicana en Perú, 1824-1826. Historia 43:79-112.

Rosenblitt, J. 2014. De arrieros a mercaderes. Orígenes de los comerciantes de la región Tacna-Arica, 1776-1794. Revista de Indias LXXIV:35-66.
Sánchez, J. 1985. Abastecimiento y desabastecimiento de pólvora en España en el S. XVI. Studia Storica: 55-62.

Sesiones de los Cuerpos Legislativos de la República 1886. Imprenta Cervantes, Santiago.

Vargas, R. 1932. Insurrección de Tacna y Tarapacá: nuevos documentos. Revista de la Universidad Católica 1:9-32.

Webster, S. 1839. Documentos que ilustran el reclamo de Santiago Webster al Gobierno del Peru por los agravios y crueldades de que fue victima durante un motin popular contra estrangeros, que estalló en Iquique en la mañana del 27 de Junio de 1835, etc. Imprenta de José Masías, Lima.

\section{Archivos y fuentes periódicas consultadas}

Archivo Administrativo de Arica (AAA).

Archivo Histórico del Ministerio de Hacienda, Expedientes oficiales (AGP 1).

Archivo Histórico del Ministerio de Hacienda, Expedientes particulares (AGP 2)

Archivo Judicial de Iquique. Causas Criminales (AJI 1).

Archivo Judicial de Iquique. Causas Civiles (AJI 2).

Archivo Notarial de Tarapacá (ANT).

Archivo del Obispado de Arequipa. Vicariato de Tarapacá. Causas penales (ARQ).

Archivo Benjamín Vicuña Mackenna (AVM).

Biblioteca Nacional del Perú. Colección Manuscritos (BNP).

Colección de leyes, decretos y órdenes publicadas en el Perú (CLDO), varias impresiones, 1831-1837.

Ministerio de Marina del Perú. Archivo Histórico. Colección Capitanía de Iquique (MMH).

Museo Nacional de Arqueología, Antropología e Historia del Perú. Material Republicano (MHP).

Registro Oficial de la República Peruana (ROP).

\section{Notas}

${ }^{1}$ Una interesante aproximación a los inicios de la explotación, desde las tradiciones regionales, en González 2016:57-62.

2 ANT, vol. 2, 6.3.1777, f. 61.

${ }^{3}$ BNP, doc. c792, 11.3.1795, s.f.

${ }^{4}$ AAA, leg. 5, p.1, 11.11.1784, f. 58.

5 ANT, vol. 6, 21.1.1800, f. 67.

${ }^{6}$ AGP 1, vol. 10, doc. 839, 11.9.1830

BNP, doc. B762, 2.4.1612.

8 AJI 2, leg. 383 , p. 3, 6.2.1807, f. 9

9 AJI 2, leg. 383, p. 3, 24.11.1807, f. 11

${ }^{10}$ AAA, leg. 12 , p. $2,19.11 .1814$, s.f.

${ }^{11}$ ANT, vol. 6, 21.8.1830, f. 174.

${ }^{12}$ AJI 1, leg. 1514, 18.8.1819, fs. 3-8.

${ }^{13}$ MHP, doc. d000374, 7.9.1827, f. 36.

${ }^{14}$ AGP 1, vol. 145, doc. 253, 19.8.1826, s.f.

${ }^{15}$ AGP 2, vol. 9, doc. 488, 17.8.1829, s.f.

${ }^{16} \mathrm{MMH}$, doc. 602, 5.9.1827, 5 de septiembre de 1827, f.1; AGP 2, vol. 10, doc. 7, 17.9.1830, s.f.

${ }^{17}$ Gazeta de Gobierno, Lima, 23.1.1828.
${ }^{18}$ ROP, 21.11.1826.

${ }^{19}$ Un caso relevante que involucra a connotados comerciantes salitreros, en AJI 1, leg. 1190, 12.2.1848, p. 6.

${ }^{20}$ AGP 2, vol. 10, doc. 272, 1.12.1829, s.f.

${ }^{21}$ ROP, 9.6.1826.

${ }^{22}$ AJI 2, leg. 6, 19.11.1829.

${ }^{23}$ AGP 1, vol. 30, doc. 272, 3.12.1829.

${ }^{24}$ AGP 2, vol. 10, doc. 793, 4.1.1881, s.f.

25 AGP 2, vol. 15, doc. 4, 7.4.1831, f. 1 .

${ }^{26}$ AGP 2, vol. 10, doc. 839, 16.9.1830, s.f.

27 AGP 2, vol. 13, doc. 7, 17.9.1832, f. 3.

28 AVM, vol. 200, 19.1.1840, f. 47

${ }^{29}$ MMH, s.n.doc., 19.4.1834, s.f.; BNPM, doc. d8734, 4.6.1834, f. 3.

${ }^{30}$ AGP 2, vol. 35, doc. 4, 5.8.1834, f. 1 .

${ }^{31}$ ARQ, p. 14, 28.1.1835, fs. 2-60.

${ }^{32}$ AGP 2, vol. 13, 26.6. - 2.12.1833, doc. 787, fs. 1-4.

33 AGP 2, vol.13, doc. 16, 19.9. 1832.

${ }^{34}$ Una descripción en ANT, vol. 6, 21.1.1800.

35 AGR 1, vol. 26, doc. 130, 12.6.1843. 